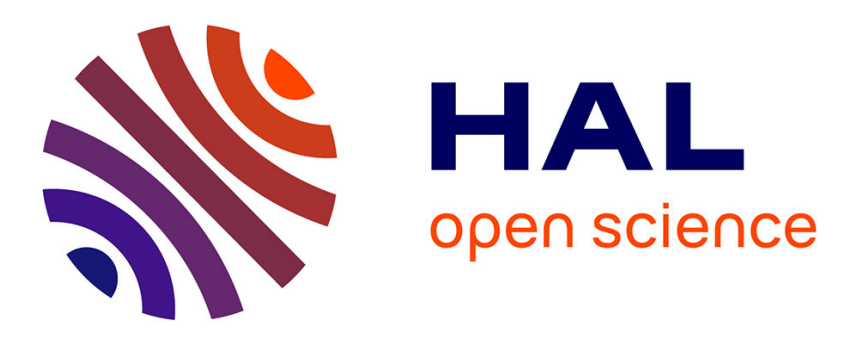

\title{
Emerging fluoroquinolone-non-susceptible group A streptococci in two different paediatric populations
}

Pierre Robert Smeesters, Anne Vergison, Dioclécio Campos Junior, Laurence van Melderen

\section{- To cite this version:}

Pierre Robert Smeesters, Anne Vergison, Dioclécio Campos Junior, Laurence van Melderen. Emerging fluoroquinolone-non-susceptible group A streptococci in two different paediatric populations. International Journal of Antimicrobial Agents, 2009, 34 (1), pp.44. 10.1016/j.ijantimicag.2009.01.012 . hal-00556328

\section{HAL Id: hal-00556328 \\ https://hal.science/hal-00556328}

Submitted on 16 Jan 2011

HAL is a multi-disciplinary open access archive for the deposit and dissemination of scientific research documents, whether they are published or not. The documents may come from teaching and research institutions in France or abroad, or from public or private research centers.
L'archive ouverte pluridisciplinaire HAL, est destinée au dépôt et à la diffusion de documents scientifiques de niveau recherche, publiés ou non, émanant des établissements d'enseignement et de recherche français ou étrangers, des laboratoires publics ou privés. 


\section{Accepted Manuscript}

Title: Emerging fluoroquinolone-non-susceptible group A streptococci in two different paediatric populations

Authors: Pierre Robert Smeesters, Anne Vergison, Dioclécio

Campos Junior, Laurence Van Melderen

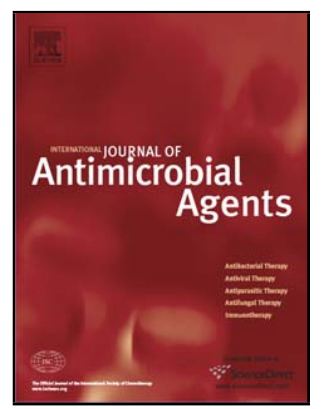

PII:

S0924-8579(09)00058-2

DOI: doi:10.1016/j.ijantimicag.2009.01.012

Reference: ANTAGE 2974

To appear in:

International Journal

of

Antimicrobial

Agents

Received date:

9-12-2008

Revised date:

13-1-2009

Accepted date:

16-1-2009

Please cite this article as: Smeesters PR, Vergison A, Junior DC, Van Melderen L, Emerging fluoroquinolone-non-susceptible group A streptococci in two different paediatric populations, International Journal of Antimicrobial Agents (2008), doi:10.1016/j.ijantimicag.2009.01.012

This is a PDF file of an unedited manuscript that has been accepted for publication. As a service to our customers we are providing this early version of the manuscript. The manuscript will undergo copyediting, typesetting, and review of the resulting proof before it is published in its final form. Please note that during the production process errors may be discovered which could affect the content, and all legal disclaimers that apply to the journal pertain. 


\section{Emerging fluoroquinolone-non-susceptible group A streptococci in two different paediatric populations}

Pierre Robert Smeesters ${ }^{\mathrm{a}, \mathrm{b}, *}$, Anne Vergison ${ }^{\mathrm{b}, \mathrm{c}}$, Dioclécio Campos Junior ${ }^{\mathrm{d}}$, Laurence Van Melderen ${ }^{a}$

a Laboratoire de Génétique et Physiologie Bactérienne, Institut de Biologie et de Médecine Moléculaires (IBMM), Faculté des Sciences, Université Libre de Bruxelles, 12 rue des Professeurs Jeener et Brachet, 6041 Gosselies, Belgium

${ }^{\mathrm{b}}$ Infectious Diseases Department, Hôpital Universitaire des Enfants Reine Fabiola, Université Libre de Bruxelles, Belgium

${ }^{\mathrm{c}}$ Epidemiology and Infection Control Unit, Hôpital Universitaire des Enfants Reine Fabiola, Université Libre de Bruxelles, Belgium

d Pediatric Department, Hospital Universitário de Brasília, Universidade de Brasília, Brazil

Received 9 December 2008; accepted 16 January 2009

Keywords: Streptococcus pyogenes; Quinolone resistance; Epidemiology; Antimicrobial resistance mechanisms; Point mutations

* Corresponding author. Tel.: +32 265097 75; fax: +32 26509770.

E-mail address: psmeeste@ulb.ac.be (P.R. Smeesters). 


\section{Abstract}

Clonal emergence of group A streptococci (GAS) with reduced susceptibility to fluoroquinolones (FQs) has been increasingly reported. Non-susceptibility is associated with various point mutations in the target-encoding genes and has only been described in a few emm types. We used a well characterised GAS clinical paediatric collection from Brussels (Belgium) and Brasília (Brazil) to analyse the molecular basis of FQ non-susceptibility. GAS strains were tested for ciprofloxacin susceptibility and were screened for mutations in DNA gyrase- and topoisomerase IV-encoding genes. Genetic relationships between the different emm types were assessed by phylogenetic analysis of the whole surface-exposed part of the $M$ protein. A high proportion (22.5\%) of ciprofloxacin-non-susceptible isolates (minimal inhibitory concentration $\geq 2 \mathrm{mg} / \mathrm{L}$ ) was found among the Belgian strains. They belonged mostly to emm type $6(87 \%)$. In Brazil, $6 \%$ of the isolates, belonging to seven distantly related emm types, were non-susceptible. Our phylogenetic analysis showed that non-susceptibility may arise in various genetic backgrounds. Sequence comparison of the quinolone resistance-determining regions (QRDRs) of the ParCand ParE-encoding genes from susceptible and non-susceptible isolates revealed that most of the mutations were found in both classes of isolates, indicating an emm type-linked polymorphism. In conclusion, we observed a clonal spreading of nonsusceptible emm type 6 GAS strains in Brussels and a polyclonal distribution of nonsusceptible isolates in Brazil. All the Brazilian and Belgian emm type 6 strains displayed a S79A/F mutation in parC that convincingly explains the non-susceptible phenotype. 


\section{Introduction}

The use of fluoroquinolones (FQs) is approved in adults for a wide range of community-acquired infections. In 2003, Belgium ranked third among European countries with the highest consumption of FQs for outpatient treatment [1]. No data on Brazilian FQ consumption are available in the literature. Paediatric use of FQs is very limited because of potential joint toxicity observed in young animal studies. Although this was not demonstrated in reports on systemic use of FQs in children $[2,3]$, these drugs are not licensed for general paediatric usage. There is, however, a trend towards increased use in this age group $[2,3]$.

FQ antibiotics target two essential bacterial type II topoisomerases: DNA gyrase, composed of four subunits encoded by the gyrA and gyrB genes; and topoisomerase IV, formed of four subunits encoded by the parC and parE genes. In Gram-positive bacteria, ciprofloxacin and levofloxacin preferentially target topoisomerase IV, whilst moxifloxacin and gatifloxacin show the converse specificity [4]. FQ resistance is mainly caused by point mutations in the target-encoding genes (gyrA, gyrB, parC and parE). Mutations tend to cluster in a defined region of these genes called the quinolone resistance-determining region (QRDR). FQ resistance appears to occur stepwise, with moderate levels of resistance arising from a single mutation in the primary target of the drug (topoisomerase IV, parC gene). A higher level of resistance is reached by the accumulation of additional mutations in the secondary target (DNA gyrase, gyrA gene) [4]. Efflux of the FQ via membrane-associated pumps also contributes to resistance $[5,6]$. 
Group A streptococci (GAS) are one of the most common paediatric pathogens. They are responsible for a wide spectrum of diseases, ranging from trivial pharyngitis and impetigo to lethal toxic shock syndrome and necrotizing fasciitis. The first description of a GAS clinical isolate resistant to ciprofloxacin [minimal inhibitory concentration $(\mathrm{MIC})>32 \mathrm{mg} / \mathrm{L})$ was reported in 2000 [7]. So far, seven cases of highly resistant strains have been described [7-11]. At the same time, GAS with reduced susceptibility to FQs have been increasingly reported worldwide $[4,12,13]$. Reduced susceptibility to ciprofloxacin was defined for GAS isolates exhibiting an MIC $\geq 2$ $\mathrm{mg} / \mathrm{L}$ [12]. The prevalence of such isolates was 3.5\% in 1998-1999 in Spain, $5.4 \%$ in 1999-2002 in Belgium and 10.9\% in 2002-2003 in the USA $[4,12,13]$. The clinical impact of this reduced susceptibility is unclear. Reduced susceptibility could represent a first step towards a higher level of resistance, hence the emergence of FQ-resistant GAS.

The epidemiology of FQ-non-susceptible GAS was reported to be clonal in developed countries [4,12,14-16], with a predominance of emm type 6 isolates [4]. We recently showed that the emm type diversity of GAS isolates was much higher in Brazil than in Belgium [17]. The aim of the present study was to compare the FQ non-susceptibility of GAS from two different clinical and microbiological settings.

\section{Material and methods}

\subsection{Materials}

GAS clinical isolates analysed in this study were prospectively collected from 1 February to 31 October 2004 from symptomatic children simultaneously in Brussels 
(Belgium) and Brasília (Brazil) [17]. Patients aged 0-15 years attending three public hospitals in Brazil and one public hospital of Brussels were included in the study. Isolates were mostly recovered from pharyngitis in Brussels and from cutaneous infections and pharyngitis in Brazil. Twenty distinct emm types were identified among 200 Belgian isolates and 48 emm types among 128 Brazilian isolates $[17,18]$. All the isolates were tested for quinolone susceptibility.

\subsection{Antibiotic susceptibility testing}

MICs for ciprofloxacin and moxifloxacin were determined by a reference broth microdilution method (Merlin-Diagnostika, Bornheim-Hersel, Germany) in cationadjusted Muller-Hinton broth (Difco Laboratories, Detroit, MI) supplemented with 4.6\% lysed horse blood as recommended by the Clinical and Laboratory Standards Institute (CLSI) [19]. Streptococcus pneumoniae ATCC 49619 was used as a control strain. GAS breakpoints for moxifloxacin were defined by the European Committee on Antimicrobial Susceptibility Testing (EUCAST) (susceptibility/resistance in mg/L: $\leq 0.5 />1)$. Non-susceptibility to ciprofloxacin was defined as an MIC $\geq 2 \mathrm{mg} / \mathrm{L}$ [12], as neither EUCAST nor CLSI breakpoints exist. The MICs for ciprofloxacin and moxifloxacin of FQ-non-susceptible isolates were determined in the presence of reserpine (an efflux pump inhibitor) at a final concentration of $25 \mathrm{mg} / \mathrm{L}$ [12].

\subsection{Epidemiological characterisation}

The relative risk of several clinical and epidemiological factors (previous antibiotherapy, crowding, sex, age, geographical location and pathology) being 
associated with the ciprofloxacin-non-susceptible phenotype was assessed separately for the Belgian and Brazilian isolates.

\subsection{Polymerase chain reaction (PCR) amplification and DNA sequencing of the} quinolone resistance-determining regions

The QRDRs of the gyrA, gyrB, parC and parE genes of the ciprofloxacin-nonsusceptible isolates were sequenced on the two DNA strands (3730 DNA Analyser; Applied Biosystems, Foster City, CA). The QRDRs of parC and/or parE of a subset of ciprofloxacin-susceptible isolates (30 strains) belonging to the same emm types as the non-susceptible isolates were also sequenced. The sequence of the primers used for PCR amplification of the QRDRs of the four target genes have been described previously [6,7]. PCR conditions were as follows: a denaturation step at 94 ${ }^{\circ} \mathrm{C}$ for $4 \mathrm{~min}$, followed by 35 cycles of $30 \mathrm{~s}$ at $94^{\circ} \mathrm{C}, 1 \mathrm{~min}$ at $50^{\circ} \mathrm{C}$ and $30 \mathrm{~s}$ at $72{ }^{\circ} \mathrm{C}$. The QRDRs sequences were compared with the gyrA (AF220945), gyrB (AE006524), parC (AF220946) and parE (AE006540) DNA sequences of the emm type 1 GAS strain (ATCC 700294).

\subsection{Phylogenetic analysis of $M$ proteins}

The genetic relatedness of the whole surface-exposed part of the M protein was analysed as described previously [20]. Briefly, the portion of the emm gene encoding the whole surface-exposed part of M (including hypervariable and conserved parts of the protein) was sequenced, translated into amino acid sequence and a multiple alignment was performed using ClustalW [21]. In the present study, the relatedness of the Belgian and Brazilian M sequences was analysed separately (19 and 46 
Belgian and Brazilian M sequences, respectively) to obtain a phylogenetic tree for each country. The sequence alignments were loaded in MEGA version 4 [22] to generate a bootstrapped tree using the neighbour-joining algorithm [23]. The evolutionary distances were computed using the Poisson correction method and are in the units of the number of amino acid substitutions per site. The variation rate among sites was modelled with a gamma distribution (shape parameter $=0.5)[20]$. The frequency of isolates of each emm type is proportional to the surface of the circle in Fig. 1.

\section{Results}

3.1. Phenotypic and epidemiological characterisation of ciprofloxacin-non-susceptible isolates

In 2004, 334 GAS isolates were collected in children presenting with GAS-associated pathologies in Brussels $(n=204)$ and Brazil $(n=130)$ [17]; 22.5\% $(46 / 204)$ of the Belgian isolates were non-susceptible to ciprofloxacin (MIC $\geq 2 \mathrm{mg} / \mathrm{L}$ ), whilst $6 \%$ $(8 / 130)$ of the Brazilian isolates were non-susceptible (Table 1). Among the 54 nonsusceptible isolates from both countries, 21 presented an MIC $\geq 4 \mathrm{mg} / \mathrm{L}$ and belonged mostly to emm type 6 (one isolate was emm type st1815). The 33 remaining isolates showed an MIC of $2 \mathrm{mg} / \mathrm{L}$ and belonged to nine different $\mathrm{emm}$ types (emm 6, 89, st1815, 59, 74, 44/61, 94, 80 and 49). All the isolates were susceptible to moxifloxacin.

From an epidemiological standpoint, the relative risk (RR) of previous antibiotherapy, crowding, sex, age or geographical location were not statistically associated with 
non-susceptibility, indicating that these factors did not constitute a risk for ciprofloxacin-non-susceptible GAS isolation in our data set. However, in Brussels, children with acute otitis media $(n=15)$ had a trend towards an increased rate of infection with non-susceptible GAS (RR $=1.9 ; P=0.09)$.

\subsection{Genotypic characterisation of ciprofloxacin-non-susceptible isolates}

Newly identified sequences were submitted to GenBank (accession nos. EF031328, EF031329, EF031330, EF031331, EF031332, EF03133 and EF529735). The 46 non-susceptible Belgian isolates belonged to three different emm types (6, 89 and st1815), among which emm type 6 was predominant (87\%) (Table 2). All the isolates carried at least one mutation in parC. The most common mutation was serine $79 \rightarrow$ alanine $(\mathrm{S} 79 \mathrm{~A})$, which was present in all emm type 6 isolates. It is noteworthy that all isolates of emm type 6 recovered were non-susceptible (MIC $\geq$ $2 \mathrm{mg} / \mathrm{L})$. Several other mutations were detected both in parC and parE. Interestingly, most of the mutations were identical for a given emm type and varied among different emm types (Table 2).

In contrast to the emm type clonality observed for the Belgian isolates, the eight nonsusceptible Brazilian isolates belonged to seven different emm types $(59,6,74$, $44 / 61,94,80$ and 49). Only three of these isolates (two emm type 59 and one emm type 6 isolates) had mutations in the parC gene, whilst four isolates carried a mutation in parE. Surprisingly, isolates of emm types 94 and 49 (both presenting an MIC of $2 \mathrm{mg} / \mathrm{L}$ ) did not carry any mutation in parC or parE. The gyrA and gyrB QRDRs sequences were wild-type for all the non-susceptible isolates and none of 
them carried an efflux resistance mechanism, as reserpine did not affect ciprofloxacin non-susceptibility.

\subsection{Genotypic characterisation of ciprofloxacin-susceptible isolates}

To determine the contribution of the mutations described above to ciprofloxacin nonsusceptibility, the QRDR sequences of the parC and parE genes from nonsusceptible isolates were compared with those from susceptible isolates belonging to the same emm types. Isolates from a given emm type within a given geographic location are usually associated with a specific clonal type as defined by multilocus sequence typing (MLST). However, three of the nine non-susceptible emm types were associated with more than one clonal type (emm 89, 44/61 and 49) [24,25].

Thirty strains from our collection belonging to the same emm types as the nonsusceptible isolates were checked for the presence of mutations in the parC and parE QRDRs (Table 3). In contrast to the st1815 non-susceptible isolates, none of the four susceptible st1815 isolates carried a S79F mutation in parC. In contrast, most of the other parC and parE mutations detected in the non-susceptible isolates were present in the corresponding susceptible isolates. The A395T and A471V mutations in parE were only observed in a fraction of the susceptible isolates, indicating a certain level of polymorphism in the parE QRDR of isolates within emm types 80, 74 and 44/61 that were isolated in Brazil. Note that the 44/61 emm type has been shown to be associated with more than one MLST clonal type [24,25]. The two Brazilian emm type 94 and 49 non-susceptible isolates that did not harbour mutations shared the same sequence as their susceptible counterparts. The S79A mutation in 
parC and the A378T mutation in parE were only found in emm type 6 for which no susceptible isolate was available in our collection.

\subsection{Phylogenetic analysis}

Figures $1 \mathrm{~A}$ and 1B represent the genetic relationships of the whole surface-exposed part of the M protein of Belgian and Brazilian isolates, respectively. The two main clades $(A$ and $B)$ of both trees correlate with the presence or absence of the serum opacity factor (sof) (which is one of the classification characteristics of GAS isolates $[26,27])$. Based on the organisation of emm and emm-like genes within the $m g a$ locus [25,28], GAS isolates can also be classified into emm patterns (A-C, D and E), which serve as an indicator of the tissue tropism. The A clades are mainly composed of emm pattern $\mathrm{E}$ ( $89 \%$ and $92 \%$ of the Brazilian and Belgian isolates, respectively), whilst the B clades are composed of emm patterns A-C and D. Fig. 1A shows that FQ-non-susceptible Belgian isolates are found in emm types that are distantly related (different Sof status and emm patterns). Similarly, Brazilian non-susceptible emm types are scattered along the tree showing that the emergence of non-susceptibility is independent of the emm type, the emm pattern and the sof status (Fig. 1B).

\section{Discussion}

Since there are no EUCAST/CLSI established breakpoints for ciprofloxacin resistance in GAS, most studies use a non-susceptibility cut-off ( $\geq 2 \mathrm{mg} / \mathrm{L})$. Using this cut-off for screening clinical isolates, as many as 14 mutations have been described in the QRDRs of parC, parE, gyrA and gyrB $[4,7-10,12,14-16,29]$ and 4 new mutations were encountered in the present study. The QRDR sequence comparison 
of susceptible and non-susceptible isolates of the same emm types revealed that the $\mathrm{S} 79 \mathrm{~F}$ in parC is a relevant mutation for ciprofloxacin non-susceptibility. This is in agreement with recent experimental data showing that mutations of S81 in gyrA and S79 in parC conferred FQ non-susceptibility and resistance [30]. These mutations were also found in the seven 'fully' resistant clinical isolates (ciprofloxacin MIC $\geq 32$ $\mathrm{mg} / \mathrm{L})$ described so far [7-11]. Our data indicate that the other mutations in parC/E and gyrA/B QRDRs are likely to represent emm type-linked polymorphism, although we cannot exclude that these mutations could be indirectly associated with FQ nonsusceptibility. These mutations were determined by comparison of the QRDR sequences of non-susceptible isolates with that of the M1 GAS reference strain (ATCC 700294). Use of this strain as a reference might not always be appropriate since emm type-linked polymorphism appears to exist (as well as some level of polymorphism inside particular emm types). To discriminate between clone-specific wild-type and mutant alleles conferring ciprofloxacin non-susceptibility, the sequence of the QRDRs of each 'wild-type' clone (belonging to an emm type and/or clonal type) should be established and made available in databases.

Because FQ resistance in Gram-positive bacteria is mediated by the accumulation of point mutations, it is intuitive to expect that resistance would emerge in different GAS genetic backgrounds. However, the molecular epidemiology of FQ resistance in a number of bacterial pathogens suggests that the persistence and spread of resistance is associated with a small number of highly successful clones [31]. The epidemiological studies of non-susceptible GAS, all of which were performed in Western countries, underlined this clonal aspect $[4,12,14-16]$. The common nonsusceptible emm types described are $6,75,89,22,28,1,5$ and 12; emm type 6 
accounted for $60-100 \%$ of the non-susceptible isolates $[4,12,14-16]$. Our data regarding the Belgian isolates are in agreement with the published data, with only three emm types involved in non-susceptibility and a large predominance of emm type $6(87 \%)$. By contrast, the eight non-susceptible Brazilian isolates belonged to seven different emm types. These emm types (59, 6, 74, 44/61, 94, 80 and 49) were different from those described in Western countries and are distantly related [20]. Thus, our data and the in vitro selection of FQ resistance [30] suggest that nonsusceptibility to FQs may emerge in a diverse array of genetic backgrounds. The apparent clonality observed in Western countries might thus be due to the reduced number of circulating emm types rather than the non-susceptible status as was proposed for FQ-resistant S. pneumoniae [32-34].

The $22.5 \%$ of ciprofloxacin-non-susceptible GAS observed in Brussels is from far the highest rate ever described in epidemiological prospective studies, particularly in a paediatric population in which FQs are not supposed to be routinely used. We propose that this very high percentage is attributable to an epidemic wave of an emm type 6 clone during the spring period (data not shown). A rapid shift in predominance of GAS emm types in the community has been demonstrated [35] and, since emm type 6 isolates harbour an intrinsic reduced susceptibility to ciprofloxacin [4], it is possible that emm type 6 has been selected, notably by the use of FQs. This hypothesis is difficult to prove. However, it is reported that Belgian doctors are prompt in prescribing quinolones $[1,36]$ and regularly prescribe topical treatment for ear infections (often containing quinolones). Topical FQ prescriptions (ear or eye drops) have been estimated to exceed 15000 per year in Belgium [12]. As children serve as one of the primary community reservoirs for both GAS and S. pneumoniae, 
topical use of FQs might contribute to the selection of FQ-non-susceptible clones and might constitute an important resistance driver.

In conclusion, we observed a clonal spreading of non-susceptible emm type 6 GAS strains in Brussels and a polyclonal distribution of non-susceptible isolates in Brazil. All the Brazilian and Belgian emm type 6 strains displayed an S79A/F mutation in parC that convincingly explains the non-susceptible phenotype. By contrast, the other non-susceptible isolates presented mutations that likely represent emm type-linked polymorphism. The molecular mechanism that confers non-susceptibility to these strains remains to be determined. It could include the plasmid-encoded quinolone resistance gene (qnr) [37], fluoroquinolone-modifying enzymes [38] and a variety of drug efflux pumps [39]. To our knowledge, these mechanisms have not or only rarely been described in GAS but may represent an interesting explanation for the wide variety of non-susceptible phenotypes linked to one given QRDR genotype.

Acknowledgments: This study was performed with the support of an academic exchange programme between the Université Libre de Bruxelles (Belgium) and the Universidade de Brasília (Brazil). The authors thank Sabina Cadar, Eurico de Aguiar, Olivier Denis, Pierre-Alexandre Drèze, Marie Hallin, Véronique Yvette Miendje Deyi and Marc Struelens for their assistance.

Funding: PRS is supported by a European Society for Paediatric Infectious Diseases (ESPID) Fellowship Award.

Competing interests: None declared. 
Ethical approval: This study was approved by the ethical board of all participating hospitals. 


\section{References}

[1] Ferech M, Coenen S, Malhotra-Kumar S, Dvorakova K, Hendrickx E, Suetens C, et al. European Surveillance of Antimicrobial Consumption (ESAC): outpatient quinolone use in Europe. J Antimicrob Chemother 2006;58:423-7.

[2] Gendrel D, Chalumeau M, Moulin F, Raymond J. Fluoroquinolones in paediatrics: a risk for the patient or for the community? Lancet Infect Dis 2003;3:537-46.

[3] Committee on Infectious Diseases. The use of systemic fluoroquinolones. Pediatrics 2006;118:1287-92.

[4] Orscheln RC, Johnson DR, Olson SM, Presti RM, Martin JM, Kaplan EL, et al. Intrinsic reduced susceptibility of serotype 6 Streptococcus pyogenes to fluoroquinolone antibiotics. J Infect Dis 2005;191:1272-9.

[5] Boos M, Mayer S, Fischer A, Kohrer K, Scheuring S, Heisig P, et al. In vitro development of resistance to six quinolones in Streptococcus pneumoniae, Streptococcus pyogenes, and Staphylococcus aureus. Antimicrob Agents Chemother 2001;45:938-42.

[6] Jones HE, Brenwald NP, Owen KA, Gill MJ. A multidrug efflux phenotype mutant of Streptococcus pyogenes. J Antimicrob Chemother 2003;51:707-10.

[7] Yan SS, Fox ML, Holland SM, Stock F, Gill VJ, Fedorko DP. Resistance to multiple fluoroquinolones in a clinical isolate of Streptococcus pyogenes: identification of gyrA and parC and specification of point mutations associated with resistance. Antimicrob Agents Chemother 2000;44:3196-8.

[8] Richter SS, Diekema DJ, Heilmann KP, Almer LS, Shortridge VD, Zeitler R, et al. Fluoroquinolone resistance in Streptococcus pyogenes. Clin Infect Dis 2003;36:380-3. 
[9] Reinert RR, Lutticken R, Al-Lahham A. High-level fluoroquinolone resistance in a clinical Streptococcus pyogenes isolate in Germany. Clin Microbiol Infect 2004;10:659-62.

[10] Rivera A, Rebollo M, Sanchez F, Navarro F, Miro E, Mirelis B, et al. Characterisation of fluoroquinolone-resistant clinical isolates of Streptococcus pyogenes in Barcelona, Spain. Clin Microbiol Infect 2005;11:759-61.

[11] Alonso R, Mateo E, Ezpeleta G, Cisterna R. Characterisation of levofloxacinresistant clinical isolates of Streptococcus pyogenes in Bilbao, Spain. Int J Antimicrob Agents 2007;30:183-5.

[12] Malhotra-Kumar S, Lammens C, Chapelle S, Mallentjer C, Weyler J, Goossens H. Clonal spread of fluoroquinolone non-susceptible Streptococcus pyogenes. J Antimicrob Chemother 2005;55:320-5.

[13] Perez-Trallero E, Fernandez-Mazarrasa C, Garcia-Rey C, Bouza E, Aguilar L, Garcia-de-Lomas J, et al. Antimicrobial susceptibilities of 1,684 Streptococcus pneumoniae and 2,039 Streptococcus pyogenes isolates and their ecological relationships: results of a 1-year (1998-1999) multicenter surveillance study in Spain. Antimicrob Agents Chemother 2001;45:3334-40.

[14] Alberti S, Cortes G, Garcia-Rey C, Rubio C, Baquero F, Garcia-Rodriguez JA, et al. Streptococcus pyogenes pharyngeal isolates with reduced susceptibility to ciprofloxacin in Spain: mechanisms of resistance and clonal diversity. Antimicrob Agents Chemother 2005;49:418-20.

[15] Alonso R, Mateo E, Galimand M, Garaizar J, Courvalin P, Cisterna R. Clonal spread of pediatric isolates of ciprofloxacin-resistant, emm type 6 Streptococcus pyogenes. J Clin Microbiol 2005;43:2492-3. 
[16] Powis J, McGeer A, Duncan C, Goren R, de Azavedo JC, Bast DJ, et al. Prevalence and characterization of invasive isolates of Streptococcus pyogenes with reduced susceptibility to fluoroquinolones. Antimicrob Agents Chemother 2005;49:2130-2.

[17] Smeesters PR, Vergison A, Campos D, de Aguiar E, Deyi VY, Van Melderen L. Differences between Belgian and Brazilian group A Streptococcus epidemiologic landscape. PLoS ONE 2006;1:e10.

[18] Smeesters PR, Campos D Jr, Van Melderen L, de Aguiar E, Vanderpas J, Vergison A. Pharyngitis in low-resources settings: a pragmatic clinical approach to reduce unnecessary antibiotic use. Pediatrics 2006;118:e1607-11.

[19] National Committee for Clinical Laboratory Standards. Methods for dilution antimicrobial susceptibility tests for bacteria that grow aerobically; approved standard. Twelfth informational supplement. Document M100-S12. Wayne, PA: NCCLS; 2002.

[20] Smeesters PR, Mardulyn P, Vergison A, Leplae R, Van Melderen L. Genetic diversity of group A Streptococcus M protein: implications for typing and vaccine development. Vaccine 2008;26:5835-42.

[21] Thompson JD, Higgins DG, Gibson TJ. CLUSTAL W: improving the sensitivity of progressive multiple sequence alignment through sequence weighting, position-specific gap penalties and weight matrix choice. Nucleic Acids Res 1994;22:4673-80.

[22] Tamura K, Dudley J, Nei M, Kumar S. MEGA4: Molecular Evolutionary Genetics Analysis (MEGA) Software Version 4.0. Mol Biol Evol 2007;24:1596-9.

[23] Saitou N, Nei M. The neighbor-joining method: a new method for reconstructing phylogenetic trees. Mol Biol Evol 1987;4:406-25. 
[24] Enright MC, Spratt BG, Kalia A, Cross JH, Bessen DE. Multilocus sequence typing of Streptococcus pyogenes and the relationships between emm type and clone. Infect Immun 2001;69:2416-27.

[25] McGregor KF, Spratt BG, Kalia A, Bennett A, Bilek N, Beall B, et al. Multilocus sequence typing of Streptococcus pyogenes representing most known emm types and distinctions among subpopulation genetic structures. J Bacteriol 2004;186:4285-94.

[26] Espinosa LE, Li Z, Gomez Barreto D, Calderon Jaimes E, Rodriguez RS, Sakota $\mathrm{V}$, et al. M protein gene type distribution among group A streptococcal clinical isolates recovered in Mexico City, Mexico, from 1991 to 2000, and Durango, Mexico, from 1998 to 1999: overlap with type distribution within the United States. J Clin Microbiol 2003;41:373-8.

[27] Beall B, Gherardi G, Lovgren M, Facklam RR, Forwick BA, Tyrrell GJ. emm and sof gene sequence variation in relation to serological typing of opacity-factorpositive group A streptococci. Microbiology 2000;146:1195-209.

[28] Bessen DE, Carapetis JR, Beall B, Katz R, Hibble M, Currie BJ, et al. Contrasting molecular epidemiology of group A streptococci causing tropical and nontropical infections of the skin and throat. J Infect Dis 2000;182:1109-16.

[29] Alonso R, Galimand M, Courvalin P. parC mutation conferring ciprofloxacin resistance in Streptococcus pyogenes BM4513. Antimicrob Agents Chemother 2002;46:3686-7.

[30] Billal DS, Fedorko DP, Yan SS, Hotomi M, Fujihara K, Nelson N, et al. In vitro induction and selection of fluoroquinolone-resistant mutants of Streptococcus pyogenes strains with multiple emm types. J Antimicrob Chemother 2007;59:2834. 
[31] Klugman KP. The role of clonality in the global spread of fluoroquinoloneresistant bacteria. Clin Infect Dis 2003;36:783-5.

[32] Davies TA, Goldschmidt R, Pfleger S, Loeloff M, Bush K, Sahm DF, et al. Cross-resistance, relatedness and allele analysis of fluoroquinolone-resistant US clinical isolates of Streptococcus pneumoniae (1998-2000). J Antimicrob Chemother 2003;52:168-75.

[33] Johnson CN, Benjamin Jr WH, Moser SA, Hollingshead SK, Zheng X, Crain MJ, et al. Genetic relatedness of levofloxacin-nonsusceptible Streptococcus pneumoniae isolates from North America. J Clin Microbiol 2003;41:2458-64.

[34] Nichol KA, Zhanel GG, Hoban DJ. Molecular epidemiology of penicillinresistant and ciprofloxacin-resistant Streptococcus pneumoniae in Canada. Antimicrob Agents Chemother 2003;47:804-8.

[35] Kaplan EL, Wotton JT, Johnson DR. Dynamic epidemiology of group A streptococcal serotypes associated with pharyngitis. Lancet 2001;358:1334-7.

[36] Goossens H, Ferech M, Vander Stichele R, Elseviers M. Outpatient antibiotic use in Europe and association with resistance: a cross-national database study. Lancet 2005;365:579-87.

[37] Jacoby GA, Walsh KE, Mills DM, Walker VJ, Oh H, Robicsek A, et al. qnrB, another plasmid-mediated gene for quinolone resistance. Antimicrob Agents Chemother 2006;50:1178-82.

[38] Robicsek A, Strahilevitz J, Jacoby GA, Macielag M, Abbanat D, Park CH, et al. Fluoroquinolone-modifying enzyme: a new adaptation of a common aminoglycoside acetyltransferase. Nat Med 2006;12:83-8.

[39] Jacoby GA. Mechanisms of resistance to quinolones. Clin Infect Dis 2005;41(Suppl 2):S120-6. 
Fig. 1. Ciprofloxacin non-susceptibility arises in distantly related emm types. The genetic relationships between the surface-exposed region of the M protein of $(A) 18$ Belgian Group A streptococci (GAS) and (B) 46 Brazilian GAS are represented. The emm types and emm patterns are indicated. The surface of the circle is proportional to the relative frequency of each emm type. The proportion of susceptible and nonsusceptible isolates within a given emm type is represented in white and black, respectively. The two main clades (A and $B$ ) correlate with the Sof status. The evolutionary history was inferred using the neighbour-joining method [23]. The tree is drawn to scale, with branch lengths proportional to the evolutionary distances. Bootstrap value $>70 \%$ are shown next to the branches (500 replicates). 
Table 1

In vitro activities of ciprofloxacin and moxifloxacin against Belgian and Brazilian isolates

\begin{tabular}{|c|c|c|c|c|c|c|c|c|c|c|c|c|}
\hline \multirow[t]{2}{*}{ City } & \multirow[t]{2}{*}{ No. of isolates } & \multirow[t]{2}{*}{ Antibiotic } & \multirow[t]{2}{*}{ No. (\%) non-susceptible isolates } & \multicolumn{9}{|c|}{ No. of isolates with MIC $(\mathrm{mg} / \mathrm{L})^{a}$} \\
\hline & & & & $\leq 0.06$ & 0.12 & 0.25 & 0.5 & 1 & 2 & 4 & 8 & 16 \\
\hline \multirow[t]{2}{*}{ Brussels } & 204 & Ciprofloxacin & $46(22.5)$ & 1 & 1 & 20 & 98 & 38 & 25 & 19 & 2 & \\
\hline & & Moxifloxacin & $0(0)$ & 7 & 94 & 62 & 38 & 3 & & & & \\
\hline \multirow[t]{2}{*}{ Brazil } & 130 & Ciprofloxacin & $8(6)$ & & & 6 & 70 & 46 & 8 & & & \\
\hline & & Moxifloxacin & $0(0)$ & 4 & 76 & 41 & 9 & & & & & \\
\hline
\end{tabular}

MIC, minimal inhibitory concentration.

${ }^{a}$ The non-susceptible breakpoint for ciprofloxacin is $\geq 2 \mathrm{mg} / \mathrm{L}$; breakpoints for moxifloxacin are $\leq 0.5 />1 \mathrm{mg} / \mathrm{L}$ for susceptibility and resistance, respectively. 
Table 2

Amino acid substitutions in topoisomerase IV subunits of ciprofloxacin nonsusceptible isolates

\begin{tabular}{|c|c|c|c|c|c|c|}
\hline \multirow[t]{2}{*}{ City } & \multirow{2}{*}{$\begin{array}{l}\text { emm } \\
\text { type }\end{array}$} & \multirow{2}{*}{$\begin{array}{l}\text { emm } \\
\text { subtype }\end{array}$} & \multirow{2}{*}{$\begin{array}{l}\text { Ciprofloxacin } \\
\text { MIC range } \\
(\mathrm{mg} / \mathrm{L})\end{array}$} & \multirow{2}{*}{$\begin{array}{l}\text { No. of } \\
\text { strains (\% } \\
\text { by city) }\end{array}$} & \multicolumn{2}{|c|}{ AA substitution(s) } \\
\hline & & & & & ParC & ParE \\
\hline \multirow[t]{7}{*}{ Brussels } & 6 & 6.0 & $2-8$ & $22(48)$ & S79A & A378T \\
\hline & & 6.14 & 8 & $1(2)$ & S79A & A378T \\
\hline & & 6.4 & $2-4$ & $13(28)$ & S79A & A378T \\
\hline & & 6.5 & $2-4$ & $4(9)$ & S79A & A378T \\
\hline & 89 & 89.0 & 2 & $3(6.5)$ & $\begin{array}{l}\text { D91N, } \\
\text { S140F }\end{array}$ & $\begin{array}{l}\text { E360D, } \\
\text { D493N }^{a}\end{array}$ \\
\hline & st1815 & st1815.0 & $2-4$ & $3(6.5)$ & S79F, & - \\
\hline & & & & & D91N & \\
\hline \multirow[t]{7}{*}{ Brazil } & 59 & 59.0 & 2 & $2(25)$ & S140P & - \\
\hline & 6 & 6.0 & 2 & $1(12.5)$ & S79A & A378T \\
\hline & 74 & 74.0 & 2 & $1(12.5)$ & - & $\mathrm{A}_{471 \mathrm{~V}^{\mathrm{a}}}$ \\
\hline & $44 / 61$ & $44 / 61.0$ & 2 & $1(12.5)$ & - & $\mathrm{A}_{471 \mathrm{~V}^{\mathrm{a}}}$ \\
\hline & 94 & 94.2 & 2 & $1(12.5)$ & - & - \\
\hline & 80 & 80.1 & 2 & $1(12.5)$ & - & $\mathrm{A} 395 \mathrm{~T}^{\mathrm{a}}$ \\
\hline & 49 & 49.3 & 2 & $1(12.5)$ & - & - \\
\hline
\end{tabular}

MIC, minimal inhibitory concentration; AA, amino acid.

a New mutation associated with a non-susceptible phenotype. 
Table 3

Distribution of parC and parE mutations according to ciprofloxacin susceptibility and emm types ${ }^{\text {a }}$

\begin{tabular}{|c|c|c|c|c|c|c|c|c|c|}
\hline & \multicolumn{4}{|l|}{ parC } & \multicolumn{5}{|l|}{ parE } \\
\hline & S79A & S79F & D91N & S140P & E360D & A378T & $\mathrm{A} 395 \mathrm{~T}^{\mathrm{b}}$ & $\mathrm{A} 471 \mathrm{~V}^{\mathrm{b}}$ & $\mathrm{D} 493 \mathrm{~N}^{\mathrm{b}}$ \\
\hline emm types & 6 & st1815 & st1815, 89 & 89,59 & 89 & 6 & 80 & $74,44 / 61$ & 89 \\
\hline No. with mutations and MIC $\geq 2 \mathrm{mg} / \mathrm{L}$ & 41 & 3 & 6 & 5 & 3 & 41 & 1 & 2 & 3 \\
\hline No. with mutations and $\mathrm{MIC}<2 \mathrm{mg} / \mathrm{L}$ & NT & 0 & 9 & 8 & 2 & NT & 1 & 1 & 2 \\
\hline No. without mutations and MIC $\geq 2 \mathrm{mg} / \mathrm{L}$ & 0 & 0 & 0 & 0 & 0 & 0 & 0 & 0 & 0 \\
\hline No. without mutations and MIC $<2 \mathrm{mg} / \mathrm{L}$ & NT & 4 & 0 & 0 & 0 & NT & 1 & 5 & 0 \\
\hline No. of strains analysed & 41 & 7 & 15 & 13 & 5 & 41 & 3 & 8 & 5 \\
\hline
\end{tabular}

MIC, minimal inhibitory concentration; NT, not tested, since no susceptible isolate was available in our collection.

${ }^{\text {a }}$ Mutations are shown for susceptible (MIC $<2 \mathrm{mg} / \mathrm{L}$ ) and non-susceptible (MIC $\geq 2 \mathrm{mg} / \mathrm{L}$ ) isolates belonging to the same emm types.

${ }^{b}$ New mutations found in this study. 
(A)

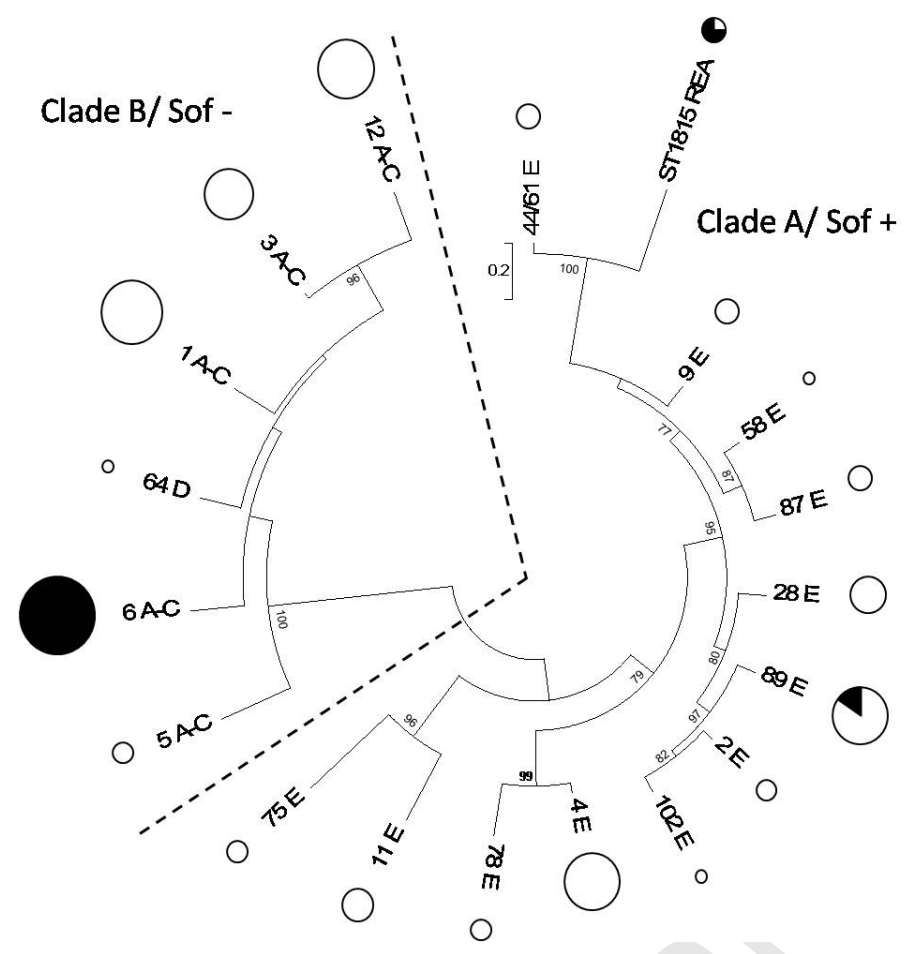

(B)

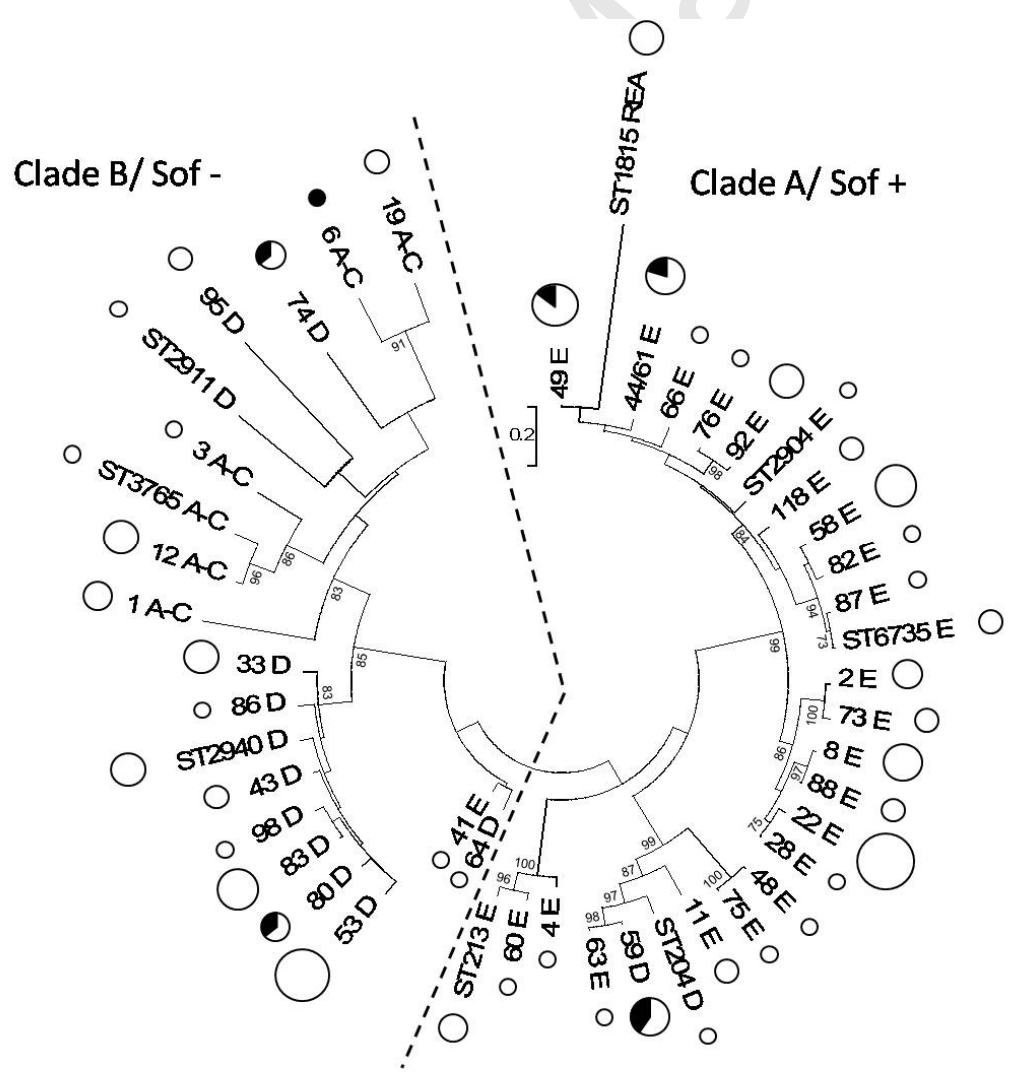

